\title{
Development of an Improved Heat Dissipation Module for LED Lamps using Multi-Layered Approach
}

\author{
S. Michael Gnanaraj \\ Lecturer-Senior Grade, Department of Mechanical Engineering, \\ Nachimuthu Polytechnic College, Pollachi, Coimbatore, Tamil Nadu, India
}

\begin{abstract}
The invention of LED lighting system has drastically revolutionized the illumination industry. LED lighting systems are being rapidly used to replace the existing lighting systems which waste a lot of energy in form of heat energy. Although LED lights produce less heat than other system, for the same illumination levels, they do possess a large level of illumination from a small source. The small source and desire to make the lighting system more and more compact has pushed many research in the area of finding more and more efficient methods of heat dissipation. Following the pattern, the objective of this study is to find an efficient and significantly improved heat dissipation module through design and analysis of the designed module using a multi layered approach. The multi layered approach relies on using a multiple layered substrates which forms the heat dissipation module which are further connected to pipes and sinks for liberating heat. In this study many analysis and simulation were done to find the natural heat convection properties of the proposed design and correlated the simulated results with the experimental results.
\end{abstract}

Key words: Heat Pipe, Heat Sink, LED, MultipleLayer Substrates, Nature Convection

\section{INTRODUCTION}

Light-emitting diodes (LEDs) are p-n junction devices constructed from semiconductor materials, such as gallium arsenide ( $\mathrm{GaAs}$ ), gallium arsenide phosphide (GaAsP), or gallium phosphide (GaP). Silicon and germanium are unsuitable for use in LEDs because these junctions produce heat with no appreciable infrared (IR) or visible light. The junction in LEDs is forward biased. When electrons cross the junction from the $\mathrm{n}$ - to the p-type material, the electron-hole recombination process produces photons in a process called electroluminescence. An exposed semiconductor surface can then emit light.

Wavelength size is related to the energy gap of the material. Materials with larger energy gaps produce shorter wavelengths [1]. Two primary approaches can be used to obtain white light from LEDs. The first method is to combine light from red, green, and blue LEDs. White light formed in this manner can be "tuned" to appear warm or cool by adjusting the amounts of each colour in the mix. The second method uses a blue LED with a phosphor coating. The coating emits a yellow light when the blue light from the LED shines on it. The mix of the yellow light with the blue light forms a white light. Inefficiency in phosphor conversion is one reason that a white LED is less efficient than a coloured LED. Some light energy is lost in the conversion to yellow [2]. LED epitaxial layers emit heat energy focused on small areas. When an LED lamp with numerous diodes is switched on, the temperature of the lamp increases rapidly as the LEDs or LED modules within emit heat. If the heat is not well dissipated, it may cause flickering and degrade the illumination quality of the LED lamp. It may also shorten the service life of the lamp. Thermal management and control are therefore major issues in solid-state lighting products. Various solutions have been proposed, as outlined below.

Kim et al. performed thermal analysis on an LED array system with a heat pipe in 2007 [3]. Their study showed that a heat pipe effectively decreased the total thermal resistance of the LED array. The heat pipe was a good solution for controlling the junction temperature of high-powered LED systems. In 2009, Lai et al. proposed an indoor LED lighting prototype 
that used pressed-flat grooved heat pipes as heat transfer channels to conduct heat emitted by LEDs to heat-sink fins [4]. Single layered heat dissipation module in the above design cannot provide a reliable solution in high power LED streetlamps.

The goal of this study was to effectively conduct heat away from a LED street lamp prototype using a multilayered heat dissipation module. The thermal performance of the proposed module was simulated and experimentally tested at different input powers.

\section{Experiment}

In JEDEC Standard No. 51-1 [5], the thermal resistance of a single semiconductor device is defined as

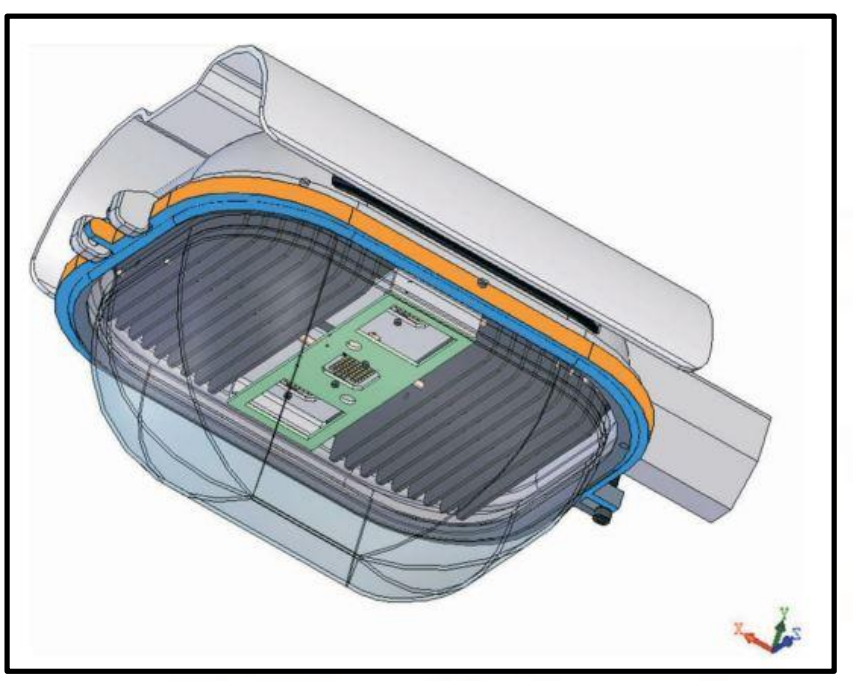

Figure 1.The Schematic of Proposed Heat Dissipation Module of LED Lamps

$$
R_{\text {total }}=\frac{T_{h}-T_{a}}{P_{\text {in }}}
$$

With, $\boldsymbol{R}_{\text {total }}$ being the thermal resistance between the LED device and the specific environment, $\boldsymbol{T}_{\boldsymbol{h}}$ being the temperature of the LED multi-chip device in a steady state condition, $\boldsymbol{T}_{\boldsymbol{a}}$ being the reference temperature for the specific environment, and $\boldsymbol{P}_{\text {in }}$ being the power dissipation in the device.

\section{Heat Dissipation Module}

Figures 1 and 2 show the schematic illustration and cross-section of the LED street lamp with heat dissipation module. The heat dissipation module included a number of substrates positioned in multiple layers. Each substrate had a multi-chip LED array mounted on a copper block conductor. As shown in Figure 2, the module had two main layers. The middle LED light source was arranged on the lower layer. The module contained three copper block conductors, nine heat pipes, and several arrays of heat sinks. LED light sources were $36 \mathrm{~mm}$ in length, $36 \mathrm{~mm}$ in width, and $19.5 \mathrm{~mm}$ in height. They were fastened tightly to copper block conductors. Each conductor was connected to the heat sinks by one vertically placed heat pipe ( $8 \mathrm{~mm}$ in diameter, $125 \mathrm{~mm}$ in length) and two horizontally placed heat pipes $(6 \mathrm{~mm}$ in diameter, $182 \mathrm{~mm}$ in length). Heat was dissipated to the heat-sink fins through the heat pipes.
The multiple-layer substrate structure was designed for optimal heat dissipation for the LED street lamp. As opposed to traditional designs, the multi-chip LED arrays were installed in a number of substrates to increase the cooling areas. This design for an LED street lamp with natural convection devices used glass shade and a DC power control system.

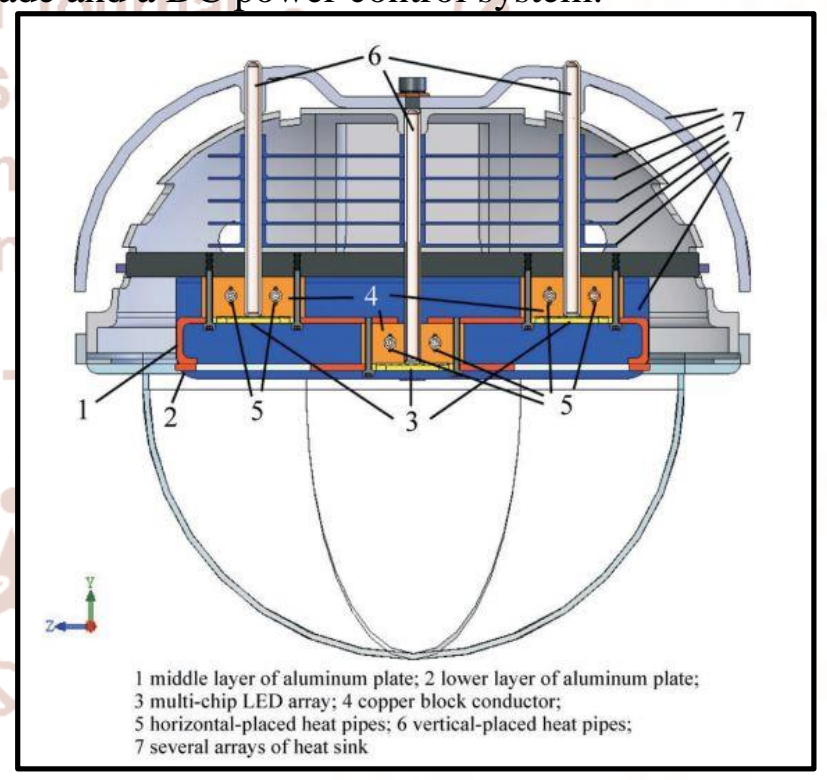

Figure 2.The C.S. View of proposed LED light Heat Dissipation Module

\section{Software Simulation Analysis}

ICEPAK software was used to analyse the heat distribution of the LED street lamp design. The simulations assumed that three LED multi-chips generated heat of 120 and $180 \mathrm{~W}$ because each multichip was 40 and $60 \mathrm{~W}$. The temperature of the environment was $30 \mathrm{C}$, a normal ambient temperature for an LED street lamp. 


\section{Fabrication and Testing}

We constructed a LED street lamp with heat dissipation module based on the model generated by ICEPAK. We spread thermal grease on the joint area to reduce contact thermal resistance. The prototype is shown in Figure 3. One LED multi-chip contained 40 single-watt LED chips connected with 10 serial connections and 4 parallel connections (Figure 4 ). The DC power supply was $350 \mathrm{~mA}$, supplying each LED multi-chip with $40 \mathrm{~W}$ by $28.6 \mathrm{~V}$ and $1.4 \mathrm{~A}$.

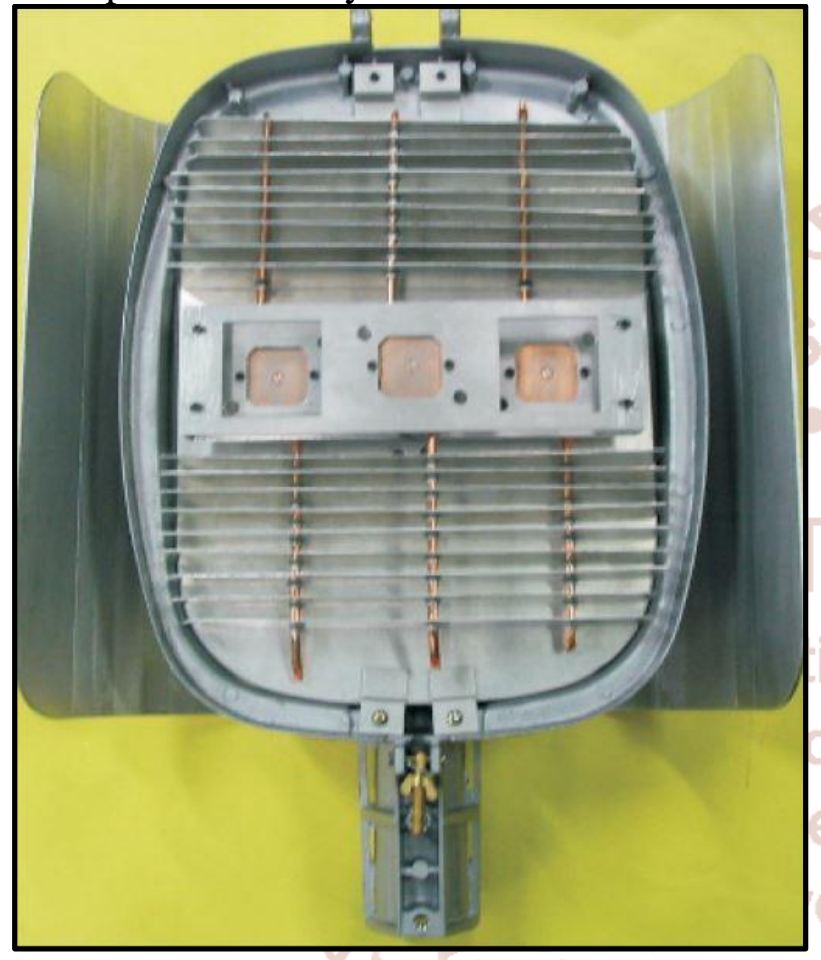

Figure 3.LED Lamp Prototype

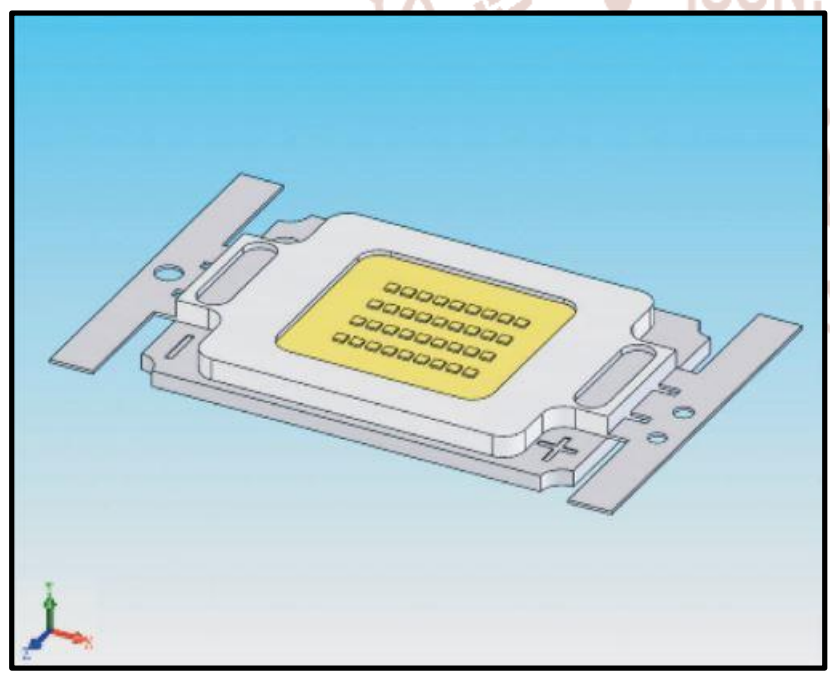

Figure 4.Model of LED Chips

Figure 5 shows the test-board built in a darkroom for gathering temperature and illuminance data. We determined the relationship between time and weakness of illuminance and calculated the thermal resistance.

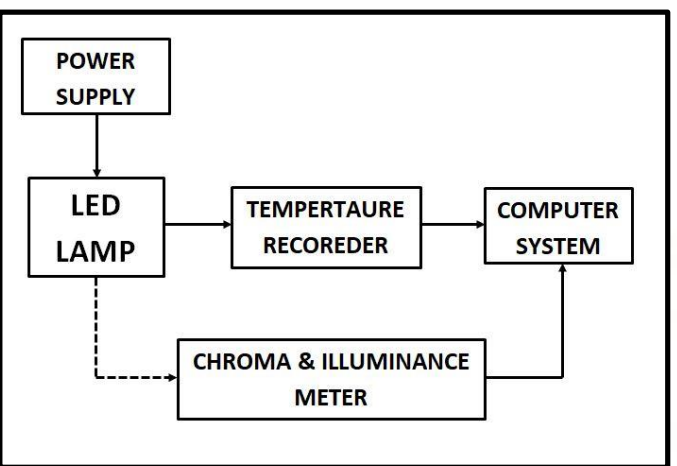

Figure 5.Block Diagram of Testing Setup

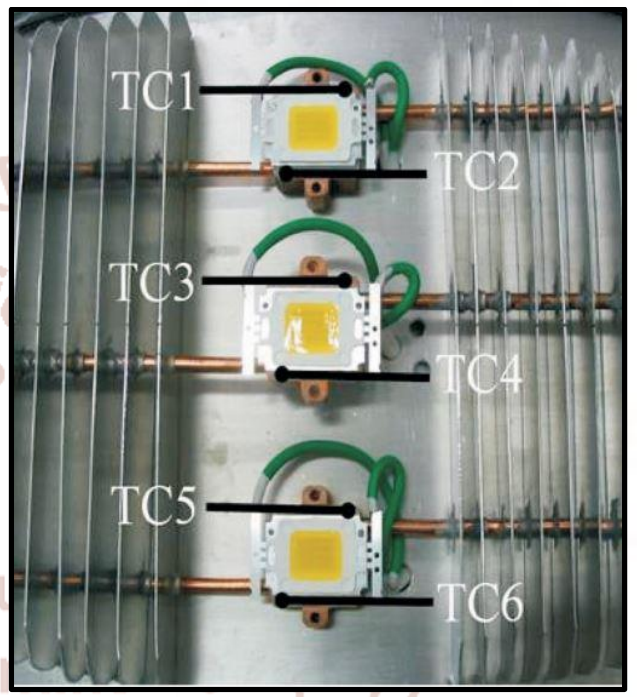

Figure 6.Picked Temperature Positions

A darkroom with natural convectional cooling conditions was necessary for testing the LED street lamp. Temperature distributions were measured with a T-type thermocouple (range of approximately $100400 \mathrm{C}$ ), as shown in Figure 6. TC1 to TC6 were the temperature measurement points on the copper block conductors

\section{Planning and Measurement}

Illuminance is one of the main considerations in an LED lamp. We used the range of light distribution to measure the performance of the LED light source to determine the optimal design for an LED lamp.

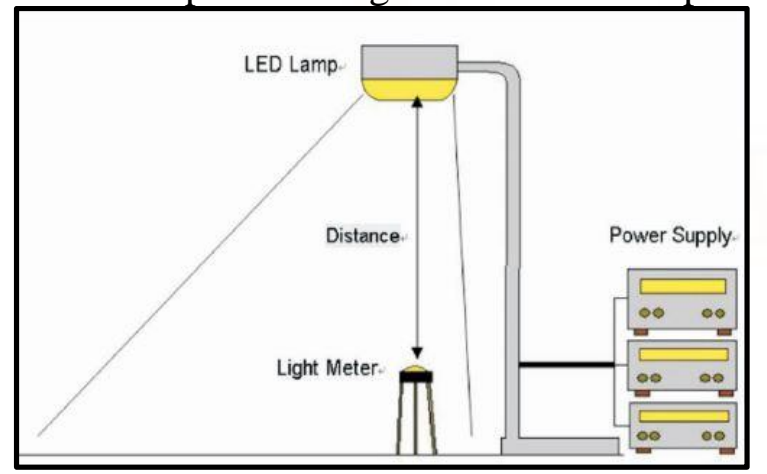

Figure 7(a).Illumination Measurement Setup Measurement Board 
Figure 7(a) shows the experimental setup for measuring the LED lamp's performance. We connected the lamp to a power supply and placed a light meter directly below the light source. We designated a $400 \times 200 \mathrm{~cm}$ rectangular area as the area to be lit by our light source. This area was divided into several smaller rectangular grids $(25 \times 25 \mathrm{~cm})$, each with four measuring points. There were a total of 153 measuring points. The lamp was centred on the edge of the area, as shown in Figure 7(b).

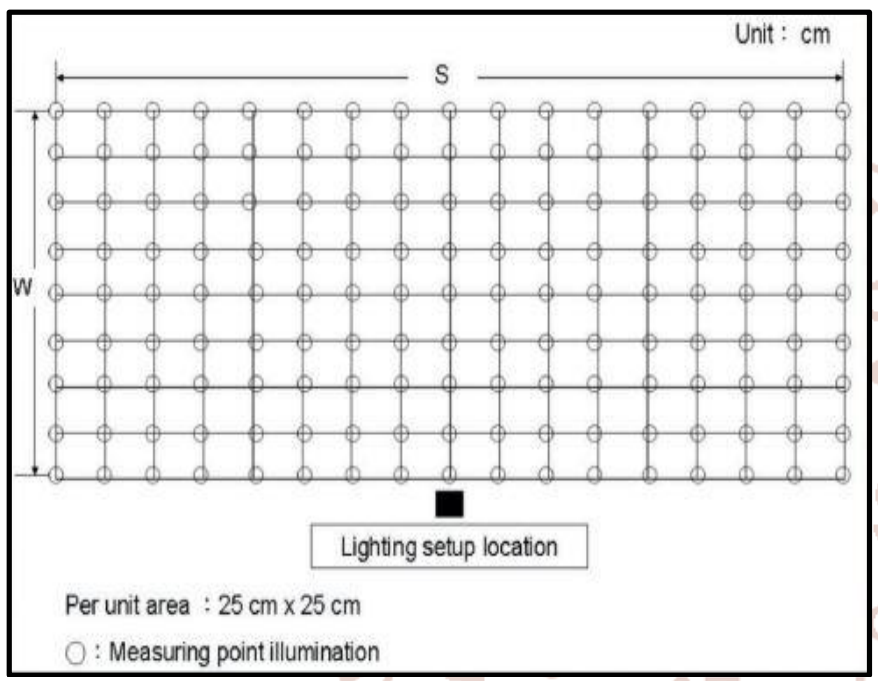

Figure 7(b).Illumination Measurement Setup Picked Points

\section{Results and Discussion}

Results of Software Simulation

Software simulations of the heat generated by the LED street lamp are shown in Table 1. Input power was set at 120 and $180 \mathrm{~W}$ and environmental temperature was set at $30{ }^{\circ} \mathrm{C}$. Temperature distributions were recorded (Figures $8 \& 9$ ). The results were used to design the heat dissipation module. This design can be replicated using the gap between the heat sink and the device, number of heat pipes, and the relationship between the components.

\section{Thermal Analysis}

AT-type thermocouple was used to record three temperatures at the LED heat sink slug. Average temperatures were compared with simulation temperatures. We determined the relationship between time of use and temperature at an input of $120 \mathrm{~W}$. Figure 10 shows that after $40 \mathrm{~min}$, the temperature gradually approached a steady state. The temperatures of the LED heat sink slug ranged from 55.6 to 57.1 ${ }^{\circ} \mathrm{C}$. The average steady state temperature of the LED heat sink slug was $56.1^{\circ} \mathrm{C}$.

The lamp's ambient temperature was between 25.2 and $29.7^{\circ} \mathrm{C}$.

At an input of $180 \mathrm{~W}$, the relationship between time of use and temperature was different. Figure 11 shows that after $30 \mathrm{~min}$, the cooling module temperature gradually approached steady-state temperatures between 65.2 and $67.4{ }^{\circ} \mathrm{C}$. The LED heat sink slug steady-state average temperature was $66.0{ }^{\circ} \mathrm{C}$. The lamp's ambient temperature was between 24.7 and $29.9^{\circ} \mathrm{C}$

In the simulation analysis, with an input of $120 \mathrm{~W}$, the LED heat sink slug's average temperature was 56.1 ${ }^{\circ} \mathrm{C}$. The simulated copper block temperature was 60.9 ${ }^{\circ} \mathrm{C}$. A $4.8^{\circ} \mathrm{C}$ difference existed between actual and simulated temperatures. At an input of $180 \mathrm{~W}$, the simulated LED heat sink slug's average temperature was $66.0^{\circ} \mathrm{C}$. The simulated temperature of the copper block was $69.3{ }^{\circ} \mathrm{C}$. A $3.3{ }^{\circ} \mathrm{C}$ existed between actual and simulated temperatures. With both differences not exceeding $5{ }^{\circ} \mathrm{C}$, little error was shown to exist between simulated and actual results (Figures 10 and 11). Figure 12 shows the overall thermal resistance of the LED lamp. At 120 and $180 \mathrm{~W}$, the average steady state value of total thermal resistance was $0.24{ }^{\circ} \mathrm{C} / \mathrm{W}$ and $0.22{ }^{\circ} \mathrm{C} / \mathrm{W}$, respectively.

Table 1.Temperature Results from Thermal Simulation

\begin{tabular}{|c|c|c|}
\hline Input Power & $120 \mathrm{~W}$ & $180 \mathrm{~W}$ \\
\hline Average temp. of LED $\left({ }^{\circ} \mathrm{C}\right)$ & $61.1^{\circ} \mathrm{C}$ & $69.45^{\circ} \mathrm{C}$ \\
\hline Average temp. of copper block $\left({ }^{\circ} \mathrm{C}\right)$ & $60.9^{\circ} \mathrm{C}$ & $69.30^{\circ} \mathrm{C}$ \\
\hline Average temp. of heat pipe $\left({ }^{\circ} \mathrm{C}\right)$ & $60.5^{\circ} \mathrm{C}$ & $68.48{ }^{\circ} \mathrm{C}$ \\
\hline Average temp. of heat sink $\left({ }^{\circ} \mathrm{C}\right)$ & $60.2^{\circ} \mathrm{C}$ & $68.23^{\circ} \mathrm{C}$ \\
\hline
\end{tabular}


International Journal of Trend in Scientific Research and Development (IJTSRD) ISSN: 2456-6470

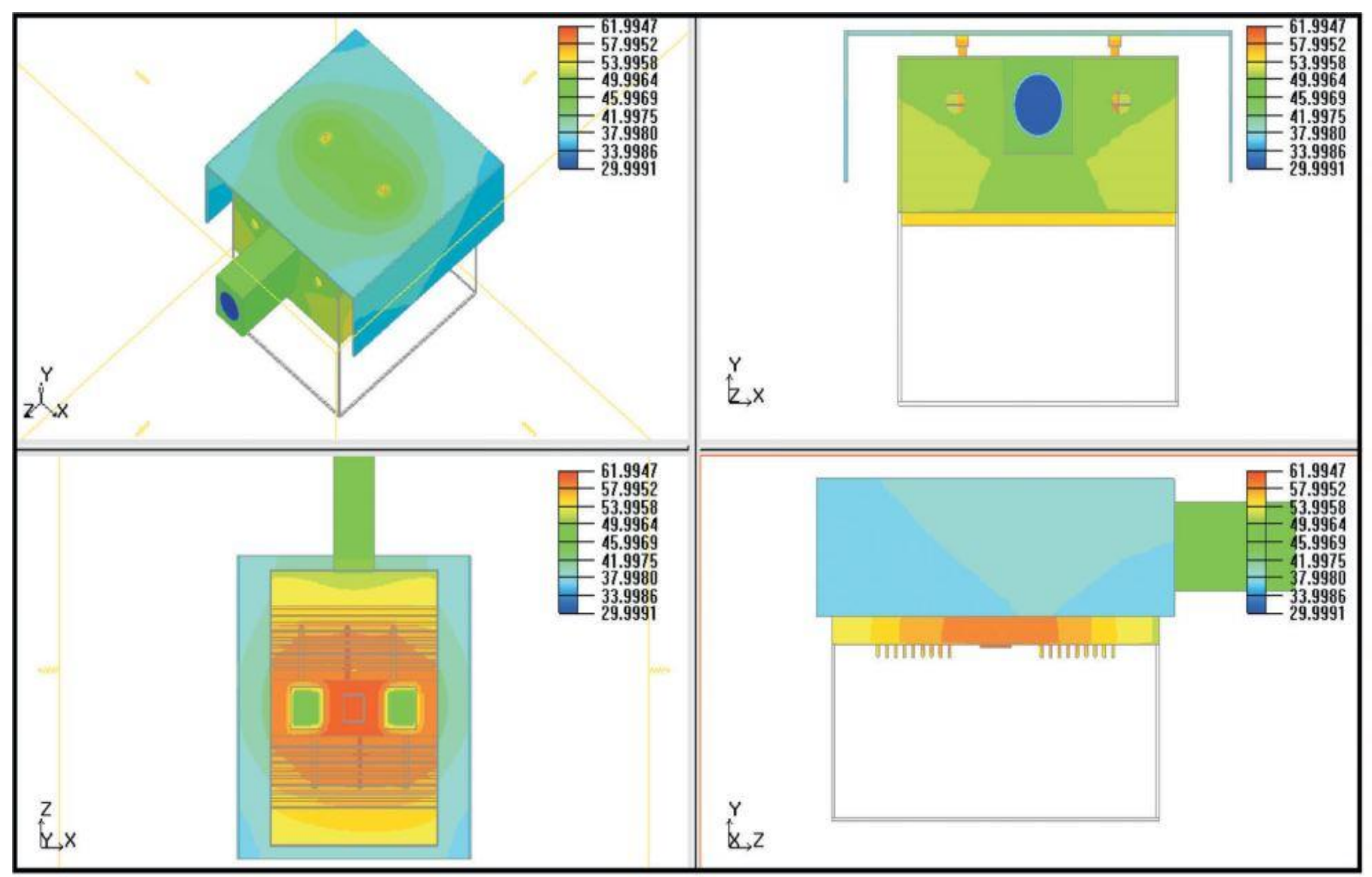

Figure 8.120 W Input Power's - Heat Dissipation Contours.

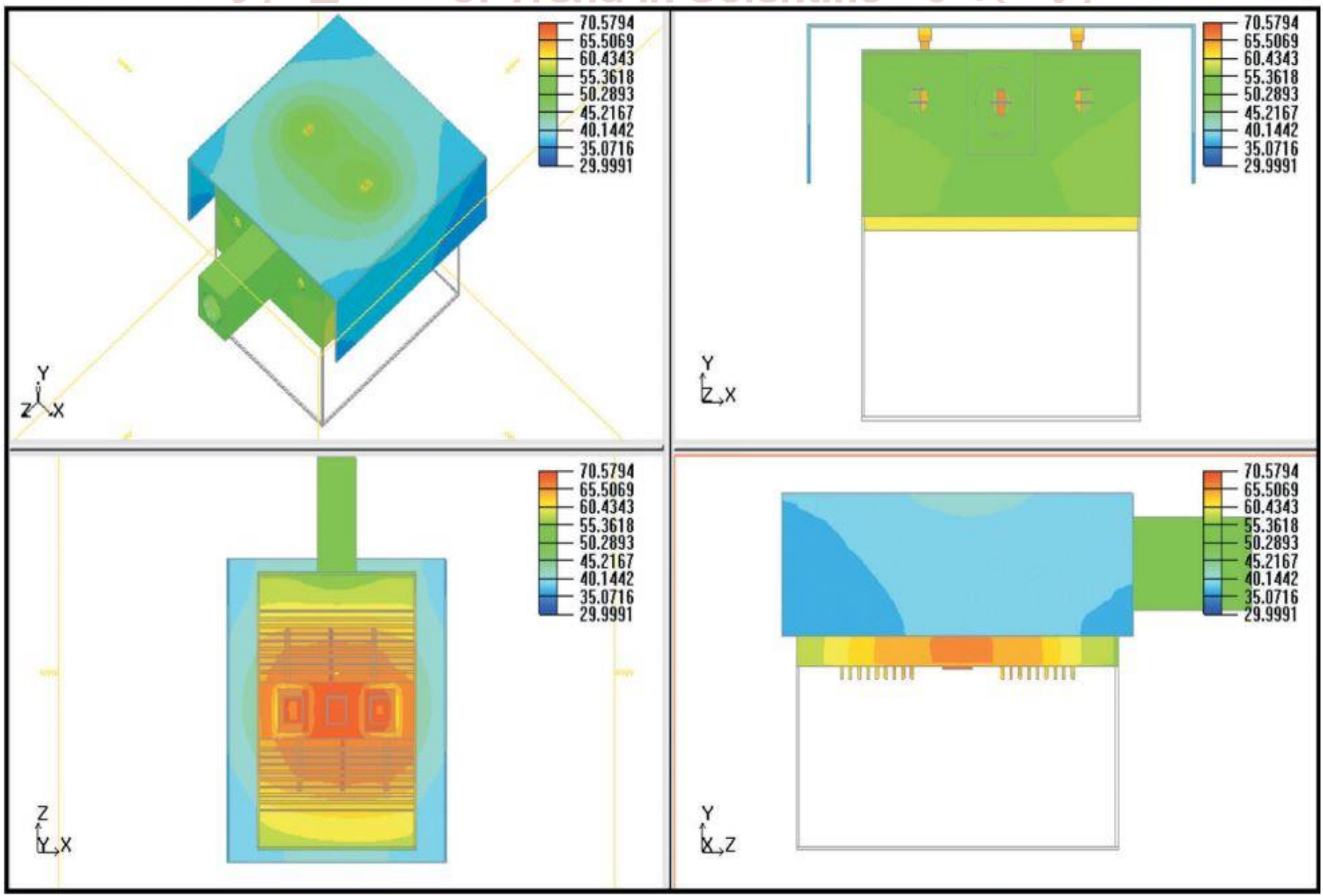

Figure 9.120 W Input Power's - Heat Dissipation Contours. 
International Journal of Trend in Scientific Research and Development (IJTSRD) ISSN: 2456-6470

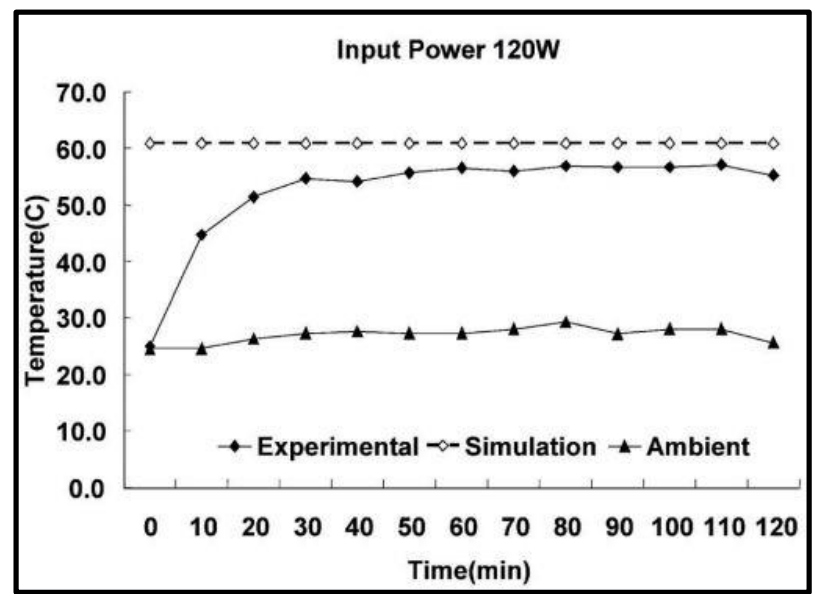

Figure 10.Temperature vs. Time Plot of 120W Input powered Heat Dissipation Module

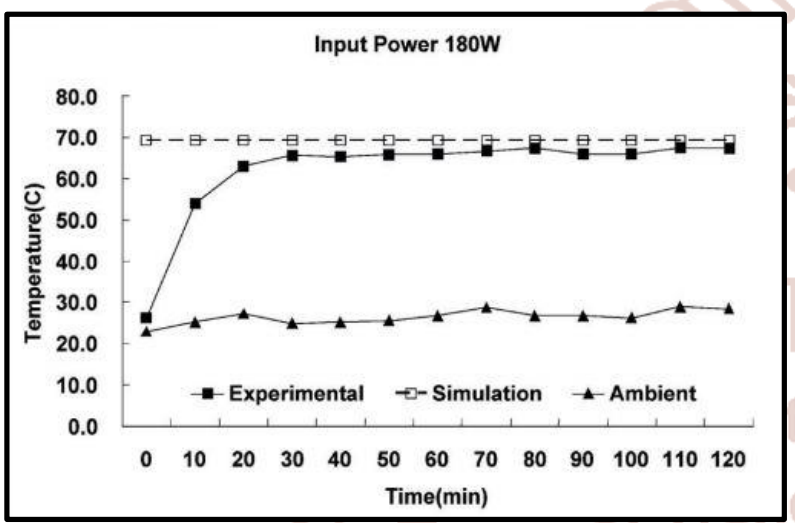

Figure 11.Temperature vs. Time Plot of 180W Input powered Heat Dissipation Module

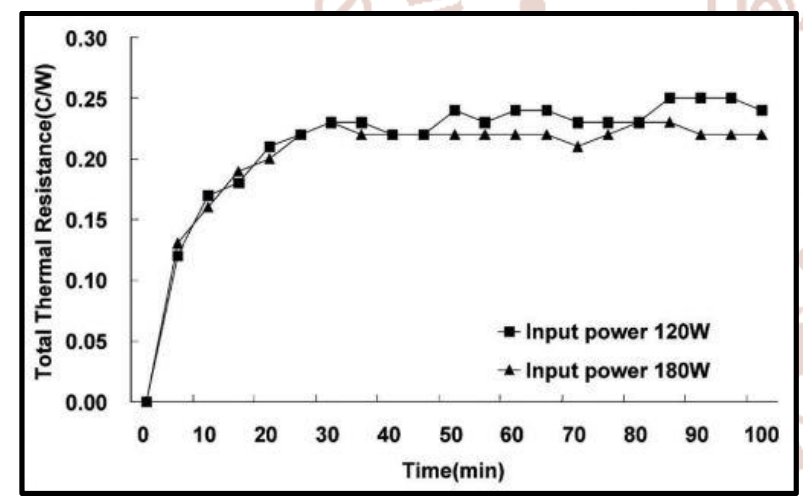

Figure 12.Total Thermal Resistance vs. Time Plot of $120 \mathrm{~W}$ and $180 \mathrm{~W}$ Input Powered Heat Dissipation Module

\section{Illuminance Analysis}

We performed an illuminance test at $120 \mathrm{~W}$. The lamp was positioned $2 \mathrm{~m}$ above the centre of the measurement location. The test area covered an area of $4 \times 2 \mathrm{~m}$ with a measurement point at each $25 \mathrm{~cm}$ interval and a total of 153 measurement points, which comprised the set of illuminance test values. After 1 min, we obtained an average illuminance of 510 lux in the centre. When the temperature reached a steady state, the average illuminance was 453 lux. We drew an illuminance plane map based on each measurement point. This showed eight levels of illuminance values. The maximum illuminance levels were in the centre between 450 and 550 lux. The centre of the illuminance distribution was in the shape of a polygonal water chestnut. The outer shape was hemispherical. This is shown in Figure 13.

We performed the same illuminance test at $180 \mathrm{~W}$. The lamp was positioned $2 \mathrm{~m}$ above the centre of the measurement location. The test area covered an area of $4 \times 2 \mathrm{~m}$ with a measurement point at each $25 \mathrm{~cm}$ interval and a total of 153 measurement points. After 1 min, we obtained an average illuminance of 670 lux in the centre. When the temperature reached a steady state, the average illuminance was 558 lux. We drew an illuminance plane map based on each measurement point. This showed nine levels of illuminance values. The maximum illuminance levels were in the centre between 550 and 600 lux. The centre of the illuminance distribution was in the shape of a polygon. The outer shape was hemispherical. This is shown in Figure 14.

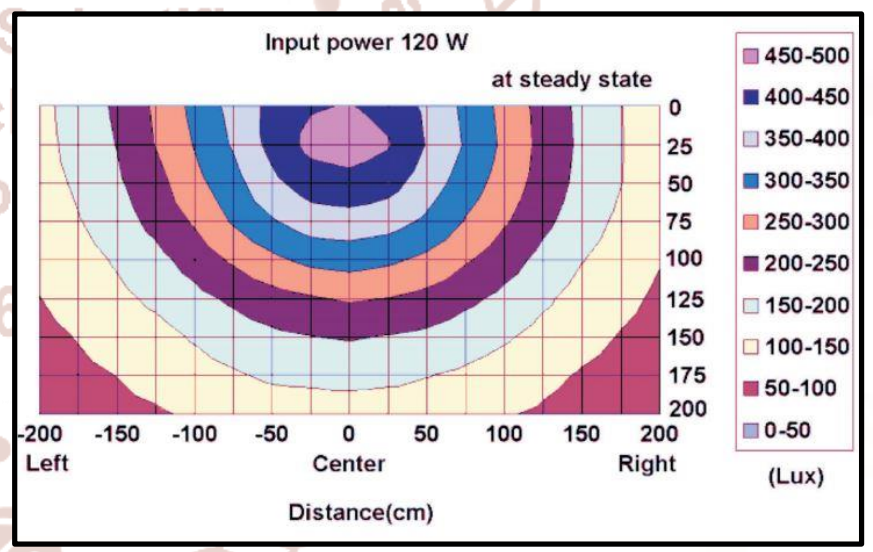

Figure 13.Distribution of Illumination for a $120 \mathrm{~W}$ Input Power

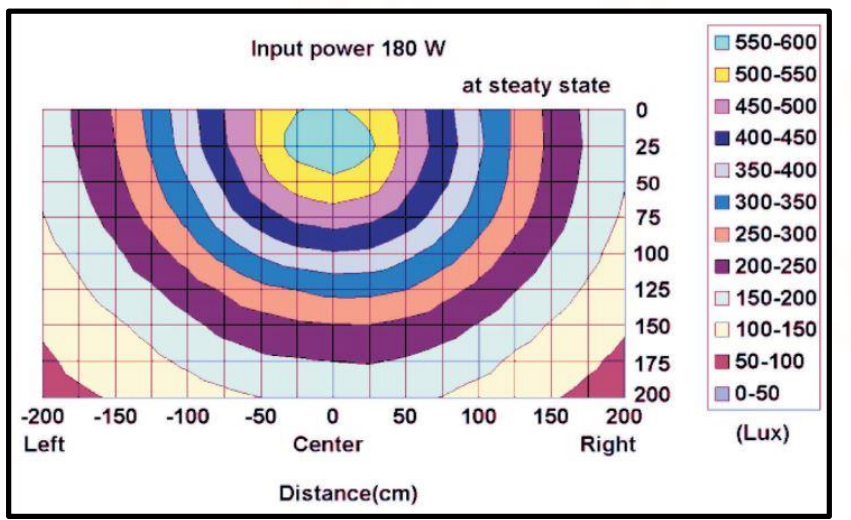

Figure 13.Distribution of Illumination for a $180 \mathrm{~W}$ Input Power 


\section{Conclusion}

This study proposed to replace traditional street lamps with an LED street lamp containing a multi-layered substrate structure for heat dissipation. We used simulation software to analyse the heat distribution for the proposed model. The simulation showed that our model would be effective at dissipating heat in the LED lamp.

We tested temperature changes at 120 and $180 \mathrm{~W}$ of inputted power. The LED heat sink slug's average temperature remained in safe ranges. Less than $5 \mathrm{C}$ differences existed between actual and simulated results. The average thermal resistance values were $0.24{ }^{\circ} \mathrm{C} / \mathrm{W}$ at $120 \mathrm{~W}$ and $0.22{ }^{\circ} \mathrm{C} / \mathrm{W}$ at $180 \mathrm{~W}$. The data showed that a multi-layered substrate structure is not only able to improve LED efficiency but also to solve the heat dissipation issue in LED lamps. Illuminance is an important consideration in lamp design. The illuminance tests showed that our LED lamp had a better illuminance distribution curve at $120 \mathrm{~W}$ than at $180 \mathrm{~W}$.

\section{References}

1. Vaccaro, P. O., "Lateral P-N Junctions for HighDensity LED Arrays," Microelectronics Journal, Vol. 34, pp. 355357 (2003).

2. Information on http://www.lumileds.com/.

3. Kim, L. J., Choi, H., Jang, S. H. and Shin, M. W., "Thermal Analysis of LED Array System with Heat Pipe," Thermochimica Acta, Vol. 455, pp. 2125 (2007).

4. Lai, C. M., Chiang, C. M. and Ho, C. J., "Thermal Performance of an Indoor Oblong LED Lighting Prototype Incorporating Heat Pipes," Journal of Asian Architecture and Building Engineering, Vol. 8, pp.585592 (2009).

5. EIA/JEDEC Standard No. 51-1, December (1995). 